\title{
Impact of Medicare's Payment Policy on Mediastinitis Following Coronary Artery Bypass Graft Surgery in US Hospitals
}

\section{Citation}

Calderwood, Michael S., Ken Kleinman, Stephen B. Soumerai, Robert Jin, Charlene Gay, Richard Piatt, William Kassler, Donald A. Goldmann, Ashish K. Jha, and Grace M. Lee. 2014. "Impact of Medicare's Payment Policy on Mediastinitis Following Coronary Artery Bypass Graft Surgery in US Hospitals." Infection Control \& Hospital Epidemiology 35 (02) (February): 144-151. doi:10.1086/674861.

\section{Published Version}

doi:10.1086/674861

\section{Permanent link}

http://nrs.harvard.edu/urn-3:HUL.InstRepos:32692606

\section{Terms of Use}

This article was downloaded from Harvard University's DASH repository, and is made available under the terms and conditions applicable to Other Posted Material, as set forth at http:// nrs.harvard.edu/urn-3:HUL.InstRepos:dash.current.terms-of-use\#LAA

\section{Share Your Story}

The Harvard community has made this article openly available. Please share how this access benefits you. Submit a story. 


\title{
Impact of Medicare's Payment Policy on Mediastinitis Following Coronary Artery Bypass Graft Surgery in US Hospitals
}

\author{
Michael S. Calderwood, MD, MPH; $;^{1,2}$ Ken Kleinman, $\mathrm{ScD}^{2}$ Stephen B. Soumerai, ScD; ${ }^{2}$ Robert Jin;, $\mathrm{MS}^{2}$ \\ Charlene Gay, BA; ${ }^{2}$ Richard Platt, MD, MSc; William Kassler, MD, MPH; ${ }^{3}$ Donald A. Goldmann, MD; ${ }^{4}$ \\ Ashish K. Jha, MD, MPH; ${ }^{5}$ Grace M. Lee, MD, $\mathrm{MPH}^{2,6}$
}

\begin{abstract}
BACKGROUnd. The Centers for Medicare and Medicaid Services (CMS) implemented a policy in October 2008 to eliminate additional Medicare payment for mediastinitis following coronary artery bypass graft (CABG) surgery.

oвjective. To evaluate the impact of this policy on mediastinitis rates, using Medicare claims and National Healthcare Safety Network (NHSN) prospective surveillance data.

METHODS. We used an interrupted time series design to compare mediastinitis rates before and after the policy, adjusted for secular trends. Billing rates came from Medicare inpatient claims following 638,761 CABG procedures in 1,234 US hospitals (January 2006September 2010). Prospective surveillance rates came from 151 NHSN hospitals in 29 states performing 94,739 CABG procedures (January 2007-September 2010). Logistic regression mixed-effects models estimated trends for mediastinitis rates.
\end{abstract}

RESULTS. We found a sudden drop in coding for index admission mediastinitis at the time of policy implementation (odds ratio, 0.36 [95\% confidence interval (CI), 0.23-0.57]) and a decreasing trend in coding for index admission mediastinitis in the postintervention period compared with the preintervention period (ratio of slopes, 0.83 [95\% CI, 0.74-0.95]). However, we saw no impact of the policy on infection rates as measured using NHSN data. Our results were not affected by changes in patient risk over time, heterogeneity in hospital demographics, or timing of hospital participation in NHSN.

CONCLUSions. The CMS policy of withholding additional Medicare payment for mediastinitis on the basis of claims-based evidence of infection was associated with changes in coding for infections but not with changes in actual infection rates during the first 2 years after policy implementation.

Infect Control Hosp Epidemiol 2014;35(2):144-151

In 2008, the Centers for Medicare and Medicaid Services (CMS) implemented a Deficit Reduction Act provision with changes to the Hospital Inpatient Prospective Payment System (IPPS), ceasing additional payment for hospital-acquired conditions (HACs) that were deemed reasonably preventable. ${ }^{1}$ CMS used billing codes to identify HACs, ${ }^{2}$ seeking to encourage hospitals to improve outcomes by removing the counterproductive incentive of reimbursing more for patients who develop complications. ${ }^{3}$

While recent work showed no impact on central catheterassociated bloodstream infection and catheter-associated urinary tract infection, ${ }^{4,5}$ the impact of the policy has not been evaluated for mediastinitis following coronary artery bypass graft (CABG) surgery. Given higher aggregate hospital costs attributable to surgical site infections, it is possible that pay- ment reform for mediastinitis may have had a greater impact in terms of reducing infections. ${ }^{6,7}$ Approximately 400,000 patients undergo CABG annually in US hospitals, ${ }^{8}$ with an average mediastinitis rate of $0.6 \%$ reported to the Centers for Disease Control and Prevention (CDC). ${ }^{9}$ This infection is associated with higher rates of repeat surgery and intensive care unit admission, longer lengths of stay, increased medical costs (more than $\$ 58,000$ per episode of mediastinitis), and higher rates of readmission and mortality. ${ }^{1,2,10-12}$

We evaluated the impact of the HAC policy on mediastinitis following CABG, comparing billing rates in Medicare claims versus prospective surveillance rates reported to the CDC's National Healthcare Safety Network (NHSN) ${ }^{13}$ We presumed that the NHSN data would provide a closer approximation of true infection rates based on standardized clinical and

Affiliations: 1. Division of Infectious Diseases, Brigham and Women's Hospital, Boston, Massachusetts; 2. Department of Population Medicine, Harvard Pilgrim Health Care Institute and Harvard Medical School, Boston, Massachusetts; 3. Centers for Medicare and Medicaid Services, Boston, Massachusetts; 4. Institute for Healthcare Improvement, Cambridge, Massachusetts; 5. Department of Health Policy and Management, Harvard School of Public Health, Boston, Massachusetts; 6. Division of Infectious Diseases and Department of Laboratory Medicine, Boston Children's Hospital, Boston, Massachusetts.

Received September 12, 2013; accepted October 31, 2013; electronically published January 8, 2014.

(C) 2014 by The Society for Healthcare Epidemiology of America. All rights reserved. 0899-823X/2014/3502-0006\$15.00. DOI: 10.1086/674861 
laboratory criteria, ${ }^{14}$ while billing data would provide insight into whether hospitals changed their billing practices as a response to the policy.

\section{METHODS}

\section{Study Population}

To examine billing rates of mediastinitis, we used Medicare Provider and Analysis Review (MedPAR) inpatient claims data from January 1, 2006, through December 31, 2010. We included data from acute care, nonfederal US hospitals, excluding critical access hospitals, long-term care hospitals, Maryland waiver hospitals, cancer hospitals, and children's inpatient facilities not subject to the IPPS rule. ${ }^{1}$

Separately, we obtained data reported to NHSN from hospitals participating in the Preventing Avoidable Infectious Complications by Adjusting Payment (PAICAP) study. ${ }^{16}$ This study recruited acute care, nonfederal US hospitals subject to the IPPS rule that were reporting on mediastinitis following CABG prior to October 1, 2008, when the HAC policy went into effect. These hospitals provided data prospectively collected by hospital staff using standardized CDC/NHSN surveillance definitions. ${ }^{14}$ We included hospitals that were reporting data between January 1, 2007, and December 31, 2010 . We did not analyze NHSN data from 2006, since only 25 of the participating hospitals were reporting mediastinitis data at that time.

We examined the demographics of US hospitals and NHSN hospitals included in our study by linking to the 2009 American Hospital Association Annual Survey Database. ${ }^{17}$ The NHSN hospitals were a subset of all US hospitals performing CABG. For the NHSN hospitals, we analyzed data on all patients undergoing CABG, while the MedPAR inpatient claims data included only Medicare patients.

\section{Study Design}

We used an interrupted time series design to evaluate the impact of the HAC policy on billing rates of mediastinitis during the index admission (ie, same hospitalization as $\mathrm{CABG}$ ) and prospective surveillance rates of mediastinitis reported to NHSN.$^{18}$ For Medicare payment purposes, the HAC policy identified mediastinitis only during the index admission.

Applying CMS criteria, we calculated billing rates of mediastinitis during the index admission using International Classification of Diseases, Ninth Revision (ICD-9) diagnosis code 519.2 not present on admission following ICD-9 procedure code $36.10-36.17$ or 36.19 . $^{2}$ We included CABG procedures performed through September 30, 2010. Given prior work showing that most surgical site infections occur after discharge, we separately calculated billing rates including coding for mediastinitis during readmission to an acute care hospital within 90 days of the CABG procedure date. ${ }^{19}$ This included surveillance for mediastinitis through December 31,
2010. Current CDC/NHSN surveillance definitions limit reporting of mediastinitis out to 90 days following a CABG procedure. ${ }^{13}$

In the prospective surveillance model, we similarly included NHSN data through September 30, 2010. This was done to mirror the billing model, with NHSN rates including postdischarge surveillance.

\section{Statistical Analysis}

All analyses were performed in SAS (ver. 9.3; SAS Institute). We used logistic regression mixed-effects models to evaluate the impact of the HAC policy on quarterly mediastinitis rates, accounting for clustering at the hospital level. We aggregated data by quarter to reduce variability. Independent variables included the policy period (before or after October 1, 2008, allowing for a change in intercept at the time of implementation), time (to adjust for secular trends), and an interaction term to determine whether the policy resulted in a change in slope.

For the claims model, we adjusted for patient-level risk factors linked to surgical site infection following CABG: age, ${ }^{20,21}$ gender, ${ }^{21,22}$ diabetes, ${ }^{20,22-25}$ obesity, ${ }^{20,22-25}$ congestive heart failure, ${ }^{26}$ renal insufficiency, ${ }^{26}$ and peripheral vascular disease. ${ }^{23,25}$ These comorbidities were identified using software (ver. 3.7) from the Healthcare Cost and Utilization Project on the basis of ICD-9 codes previously reported by Elixhauser et al. ${ }^{27,28}$

For the prospective surveillance model, we adjusted for the NHSN risk index, which was reported for all procedures. The NHSN risk index is a composite score incorporating data on a patient's preoperative health status, duration of operation, and any wound contamination at the time of surgery; this score is used to predict the risk of surgical site infection following an operation. ${ }^{29}$ The NHSN data set did not include the covariates selected for risk adjustment in the claims model.

To assess the completeness of case capture using coding for mediastinitis during the index admission, we evaluated the proportion of mediastinitis cases coded during the index admission or during readmission to an acute care hospital within 90 days of the CABG procedure date. A $\chi^{2}$ test was used to compare this proportion in the 2 study periods. We also quantified the average length of stay in the 2 study periods to help understand any changes in index admission versus postdischarge case capture.

In the claims model and the prospective surveillance model, we evaluated whether our findings were affected by changes in patient risk over time by modeling our outcome without covariates for patient-level risk factors. For the claims model, we also looked at effect modification by (1) type of ownership (for-profit vs not-for-profit vs public) and (2) percentage of Medicare patients analyzed by quartile. This was done to evaluate whether certain hospitals responded differently to the HAC policy in terms of billing for mediastinitis. 
Finally, for the prospective surveillance model, we performed a sensitivity analysis including only hospitals reporting at both the beginning of the study (2007 quarter 1) and the end of the study (2010 quarter 3 ). This was done to address concerns that if hospitals with higher-risk patients joined later in the study period, they might mask a true decline in mediastinitis rates.

\section{RESULTS}

\section{Study Population}

There were 1,234 acute care, nonfederal US hospitals subject to the IPPS rule that performed CABG procedures on Medicare patients between January 1, 2006, and September 30, 2010. Among the 398 hospitals participating in the PAICAP study between January 1, 2007, and September 30, 2010, 151 hospitals from 29 states reported CABG data to NHSN. Table 1 shows the demographic features of hospitals included in the study. The subset of US hospitals in the NHSN study group tended to be larger (400 beds or more), not-for-profit, major teaching hospitals. This group also had a higher proportion of hospitals from the northeast portion of the country.

\section{Billing Rates of Mediastinitis during Index Admission}

Following 638,761 CABG procedures performed on Medicare patients between January 1, 2006, and September 30, 2010, only 352 patients $(0.06 \%)$ were coded as having mediastinitis during the index admission. Figure 1 shows a plot of quarterly mediastinitis rates using coding for this event during the index admission. Coding for index admission mediastinitis was increasing during the baseline period (slope, 1.09 [95\% confidence interval (CI), 1.01-1.16]). After the start of the HAC policy, there was an immediate drop, with a relative odds of coding for index admission mediastinitis of 0.36 , comparing coding in quarter 4 versus quarter 32008 ( $95 \%$ CI, 0.23-0.57). Finally, there was a decreasing trend in coding

TABLE 1. Characteristics of US Hospitals and National Healthcare Safety Network (NHSN) Hospitals Performing Coronary Artery Bypass Graft Surgery in Our Study Populations

\begin{tabular}{|c|c|c|}
\hline Characteristic & US hospitals $(n=1,234)^{\mathrm{a}}$ & NHSN hospitals $(n=151)^{\mathrm{b}}$ \\
\hline \multicolumn{3}{|l|}{ Region } \\
\hline Midwest & $329(27)$ & $36(25)$ \\
\hline Northeast & $159(13)$ & $70(48)$ \\
\hline South & $451(38)$ & $19(13)$ \\
\hline West & $259(22)$ & $20(14)$ \\
\hline \multicolumn{3}{|l|}{ Location } \\
\hline Metro & $1,115(93)$ & $137(95)$ \\
\hline Micro & $78(7)$ & $8(6)$ \\
\hline Rural & $5(<1)$ & $0(0)$ \\
\hline \multicolumn{3}{|l|}{ Bed size } \\
\hline$<100$ & $46(4)$ & $1(1)$ \\
\hline $100-399$ & $757(63)$ & $71(49)$ \\
\hline$\geq 400$ & $395(33)$ & $73(50)$ \\
\hline \multicolumn{3}{|l|}{ Type of ownership } \\
\hline For-profit & $238(20)$ & $9(6)$ \\
\hline Not-for-profit & $831(69)$ & $121(83)$ \\
\hline Public & $129(11)$ & $15(10)$ \\
\hline \multicolumn{3}{|l|}{ Teaching status } \\
\hline Graduate & $314(26)$ & $39(27)$ \\
\hline Major & $234(20)$ & $61(42)$ \\
\hline Minor & $87(7)$ & $6(4)$ \\
\hline Nonteaching & $563(47)$ & $39(27)$ \\
\hline \multicolumn{3}{|c|}{ Full-time equivalent nurses ${ }^{c}$} \\
\hline Median & 7.0 & 7.2 \\
\hline Interquartile range & $5.8-8.4$ & $6.0-8.5$ \\
\hline \multicolumn{3}{|c|}{ Medicare admissions, $\%$} \\
\hline Median & 44 & 42 \\
\hline Interquartile range & $38-50$ & $37-48$ \\
\hline
\end{tabular}

NOTE. Data are no. (\%), unless otherwise indicated.

a 36 hospitals with missing American Hospital Association (AHA) data.

b 6 hospitals with missing AHA data.

'Data are no. of nurses per 1,000 patient-days. 


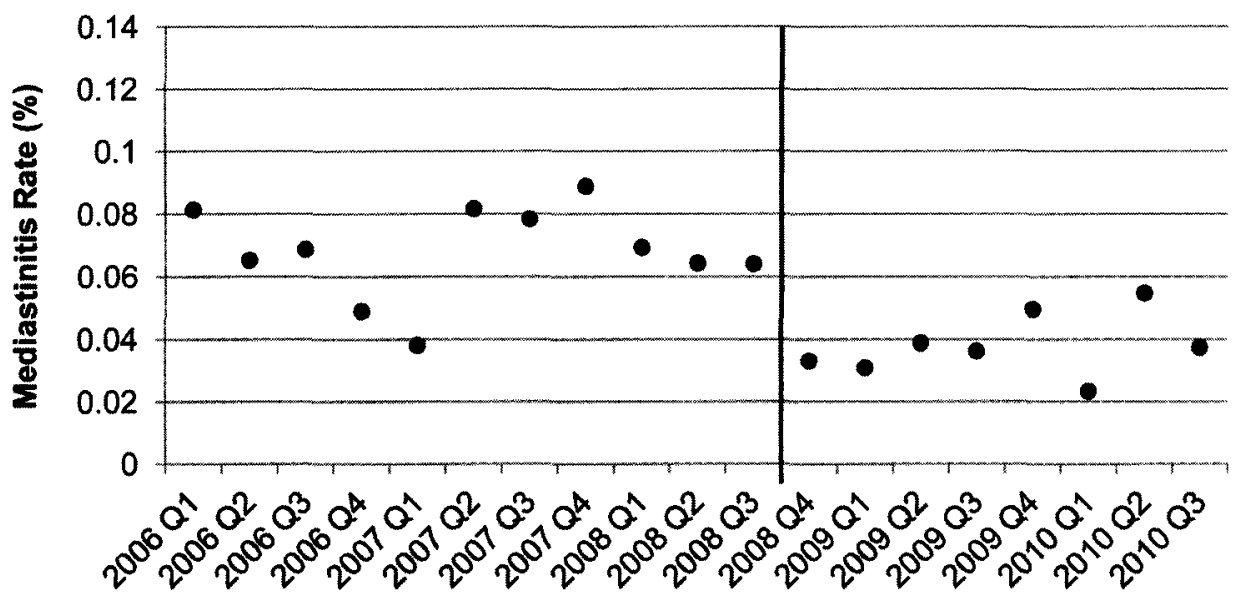

FIGURE 1. Quarterly rates of index admission mediastinitis based on Medicare claims data. Vertical line indicates start date of Centers for Medicare and Medicaid Services hospital-acquired condition policy.

for index admission mediastinitis in the postintervention period compared with the preintervention period (ratio of slopes, 0.83 [95\% CI, 0.74-0.95]).

\section{Prospective Surveillance Rates of Mediastinitis}

Hospitals participating in the PAICAP study reported 94,739 CABG procedures to NHSN between January 1, 2007, and September 30, 2010, with mediastinitis reported following 372 procedures $(0.39 \%)$. Figure 2 shows a plot of quarterly mediastinitis rates for these hospitals. The rate of mediastinitis reporting was stable in the baseline period (slope, 1.04 [95\% $\mathrm{CI}, 0.94-1.15]$ ), and there was no immediate drop in reporting following intervention (relative odds for quarter 4 vs quarter $32008,1.04$ [95\% CI, 0.71-1.51]). There was also no change in reporting trends in the postintervention period compared with the preintervention period (ratio of slopes, 0.92 [95\% CI, 0.82-1.04]).

\section{Billing Rates Including Postdischarge Data}

Including patients with a mediastinitis code on readmission to an acute care hospital within 90 days of surgery, the number of patients with a code for mediastinitis increased to 1,628 $(0.25 \%)$. Figure 3 shows quarterly mediastinitis rates based on this extended surveillance window, with index admission mediastinitis rates repeated from Figure 1 for comparison. Prior to the HAC policy, $27 \%$ of patients with a mediastinitis code within 90 days of surgery had a billing code for mediastinitis during their index admission. This dropped to $14 \%$ in the postintervention period, a significant change $(P<.01)$. The average length of stay for the index admission was 10.9 days in the preintervention period and 10.6 days in the postintervention period.

\section{Alternative Analyses}

Our main findings for the claims model were the same when not accounting for coded comorbidities. While the increase in the preintervention slope was no longer significant, both the immediate drop and the decreasing trend in coding for index admission mediastinitis in the postintervention period remained significant in the non-risk-adjusted model. Similarly, the findings for the prospective surveillance model were the same with and without risk adjustment for the NHSN risk index. This suggests that our findings were not affected by changes in patient risk over time. Additionally, in evaluating coding for index admission mediastinitis, we did not observe a differential response to the HAC policy in terms of different slopes over time by type of ownership or by percentage of Medicare patients analyzed by quartile $(P>$ .05 for all interactions). Finally, in the prospective surveillance model, our findings were the same when limited to PAICAP hospitals that consistently reported surgical site infection results during the entire study period, suggesting that the inclusion of hospitals joining later in the study period did not affect our finding that the HAC policy had no impact on the rate of infections reported.

\section{DISCUSSION}

The CMS policy of withholding additional Medicare payment for mediastinitis following CABG appears to have been associated with a sudden drop in coding for mediastinitis at the time of policy implementation and a decreasing trend in coding in the postintervention period. There was no discernible impact, however, on surveillance infection rates within the first 2 years of policy implementation. These findings suggest that while hospitals changed coding practice, 


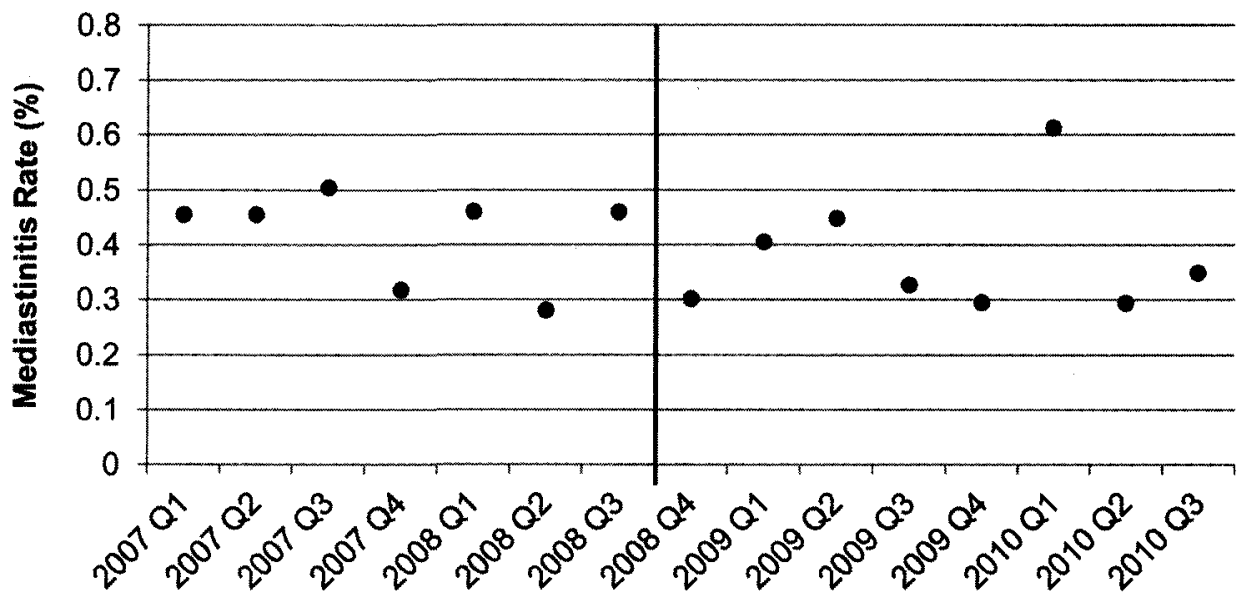

FIGURE 2. Quarterly rates of mediastinitis based on prospective National Healthcare Safety Network surveillance. Vertical line indicates start date of Centers for Medicare and Medicaid Services hospital-acquired condition policy.

clinical outcomes did not significantly change in the time period studied. In interpreting these results, it is important to note that most CMS claims for mediastinitis following CABG were submitted during readmissions rather than during the index hospitalization that was subject to the new policy. This was true even before the policy was implemented, but there was a significant decrease in the percentage of total mediastinitis cases identified by claims during the index admission compared with readmission following implementation of the HAC policy.

These findings highlight the importance of choosing the right metric and understanding its intended purpose. Billing codes can be used to target review of patient records for surgical site infections following CABG, but prior approaches have typically relied on multiple codes to account for coding variation, with tracking over a longer period to capture postdischarge events. ${ }^{30-32}$ While these broader approaches have been successful for auditing surveillance activity, ${ }^{32-34}$ the goals are different when using codes to determine payment. It is important that the codes selected for a payment policy have a high specificity, meaning that they are rarely used except for the targeted outcome. The challenge with such an approach is that billing practices vary substantially across hospitals, making it difficult for the policy to reliably capture adverse events. ${ }^{35}$ Additionally, in the case of surgical site infections such as mediastinitis, the adverse events often occur after the patient has left the hospital. Thus, policies to address these infections should consider addressing these postdischarge events.

To our knowledge, this is the first study to demonstrate that the CMS HAC policy resulted in changes in coding practice. This work also adds to growing evidence suggesting that the HAC policy has not yet improved trends in the healthcareassociated infections being targeted. ${ }^{4,5}$ This outcome was previously predicted by $\mathrm{McNutt}$ et $\mathrm{al}^{36}$ in a discussion about the likely cost savings for CMS from the HAC policy. In its original form, the $2008 \mathrm{CMS}$ HAC policy was intended to remove the perverse incentive of paying an additional amount for preventable complications occurring during hospitalization. This policy was one of the first national attempts in the United States to utilize financial disincentives as a lever for improving hospital quality of care. While the impact of pay-for-performance policies on outcomes in hospital settings has been mixed ${ }^{37-41}$ the HAC policy has definitely increased awareness of healthcare-associated infections among hospital leadership with a greater focus on what is being publicly reported. ${ }^{42,43}$

In interpreting our findings, we note some limitations. First, our access to patient-level NHSN data was limited to hospitals participating in the PAICAP study. We therefore may have insufficient power to detect a change in the NHSN data, although the estimates from our models were all close to the null value, suggesting no change. Second, the hospitals included in the prospective surveillance model were a subset of the hospitals included in the billing model. In addition, we analyzed data on all patients undergoing CABG in the prospective surveillance model, while the billing model included data from only Medicare patients. We can therefore not directly compare the rates in these 2 groups. Instead, our study compares the impact of the CMS HAC policy in these 2 different data sources - one focused on billing and the other on prospective surveillance for infections. Third, the factors available for risk adjustment differed in the billing and prospective surveillance models. Our results, however, were similar with and without risk adjustment in each model. Fourth, in our billing model of index admission mediastinitis, it is possible that the increasing slope in the baseline period may have been influenced by outlier rates of coding for index admission mediastinitis in 2006 quarter 4 and 2007 quarter 1 , but the drop in coding for this event following the HAC policy was sustained through the end of the study period in 


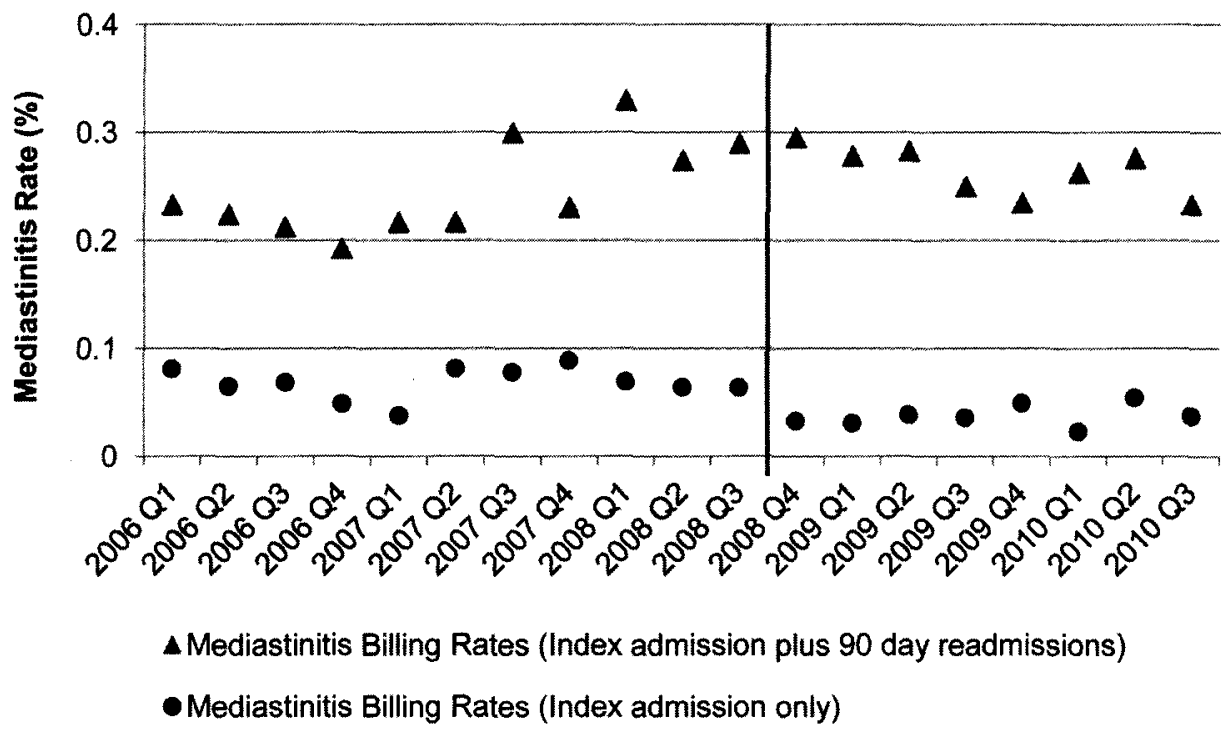

FIGURE 3. Quarterly rates of mediastinitis during the index admission and within 90 days of surgery based on Medicare claims data. Vertical line indicates start date of Centers for Medicare and Medicaid Services hospital-acquired condition policy.

2010 quarter 3. Finally, it is possible that increases in offpump or minimally invasive CABG procedures may account for some change in the rates of mediastinitis over time in the claims data, although this is unlikely to explain the sudden drop at the time of policy implementation.

As of this writing, CMS continues to refine their policies, including current requirements that hospitals report data on certain healthcare-associated infections to the CDC's NHSN, with a plan to use these data in the Hospital Inpatient ValueBased Purchasing Program. ${ }^{44-46}$ CMS is making this NHSN surveillance data publicly available on the Hospital Compare website. ${ }^{47} \mathrm{CMS}$ also recently proposed to use NHSN measures for the healthcare-associated infection domain of the HAC reduction program mandated by the Affordable Care Act. This represents a shift away from claims-based measures for public reporting of healthcare-associated infections.

Overall, we conclude that the CMS HAC policy did not reduce rates of mediastinitis following CABG during the first 2 years after the policy was implemented. This may in part be due to the fact that mediastinitis is a rare outcome that most commonly occurs after a patient has been discharged, while the HAC policy focused on events during the surgical admission. Going forward, policymakers will continue to face many challenges in evaluating the ongoing impact of financial disincentives as CMS moves toward the use of NHSN data. Nonetheless, it remains a worthy goal to minimize patient harm and to continue efforts to align quality and payment in US hospitals.

\section{ACKNOWLEDGMENTS}

We thank the hospitals for participating in the Preventing Avoidable Infectious Complications by Adjusting Payment (PAICAP) study that provided data on mediastinitis following coronary artery bypass graft procedures, including Advocate Sherman Hospital (Elgin, IL), Altoona Regional Health System (Altoona, PA), Boston Medical Center (Boston, MA), Carle Hospital and Physician Group (Urbana, IL), Greenville Health System (Greenville, SC), Keck Hospital of University of Southern California (Los Angeles, CA), Louis Weiss Memorial Hospital (Chicago, IL), Memorial Hospital (Belleville, IL), NewYork-Presbyterian Hospital (New York, NY), NorthShore University HealthSystem (Evanston, IL), Northwestern Memorial Hospital (Chicago, IL), Penn Presbyterian Medical Center (Philadelphia, PA), Porter Adventist Hospital (Denver, CO), Saint Luke's Hospital (Kansas City, MO), St. Vincent Hospital (Indianapolis, IN), Thomas Jefferson University Hospitals (Philadelphia, PA), University of California Irvine Health (Orange, CA), Vassar Brothers Medical Center (Poughkeepsie, NY), and 133 additional hospitals that wish to remain anonymous. We are grateful to our research study staff (Danielle Schroth, BA; Tricia Kennedy, BA; Hilana Bernheimer, BA; Nandini Vijayakumar, BA; Alise Dumais, BA; Donna Rusinak, BA; and Andrea Moreira, $B A$ ) for recruitment and administrative support, our infection prevention specialists (Kathy Flaherty, BA; Ashley Tracy, BA; Laura Helsing, BA; and Gail Potter-Bynoe, BS) for their assistance with recruitment, and the members of the PAICAP advisory board (John Jernigan, MD, MS; Scott Fridkin, MD; Teresa Horan, MPH; Patti Grant, RN, BSN, MS; Neil Fishman, MD; Victoria Fraser, MD; Robert Weinstein, MD; Jean Marie Mayer, MD; Susan Huang, MD, MPH; and Deborah Yokoe, MD, MPH) for their guidance and input. The views expressed in this article represent the authors and not necessarily the Centers for Medicare and Medicaid Services.

Financial support. G.M.L. received grant support from the Agency for Healthcare Research and Quality (5R01HS018414).

Potential conflicts of interest. All authors report no conflicts of interest relevant to this article. All authors submitted the ICMJE Form for Disclosure of Potential Conflicts of Interest, and the conflicts that the editors consider relevant to this article are disclosed here.

Address correspondence to Michael S. Calderwood, MD, MPH, Division of Infectious Diseases, Brigham and Women's Hospital, 181 Longwood Avenue, MCP Building, 5th Floor, Boston, MA 02115 (mcalderwood@partners.org).

\section{REFERENCES}

1. Centers for Medicare and Medicaid Services; Department of 
Health and Human Services. Medicare program: changes to the hospital inpatient prospective payment systems and fiscal year 2008 rates. Fed Regist 2007;72(162):47379-47428.

2. Centers for Medicare and Medicaid Services (CMS). HospitalAcquired Conditions. Baltimore: CMS, 2012. http://www.cms .gov/Medicare/Medicare-Fee-for-Service-Payment/Hospital AcqCond/. Accessed September 11, 2013.

3. Rosenthal MB. Non-payment for performance? Medicare's new reimbursement rule. $N$ Engl J Med 2007;357(16):1573-1575.

4. Lee GM, Kleinman K, Soumerai SB, et al. Effect of nonpayment for preventable infections in U.S. hospitals. $N$ Engl J Med 2012; 367(15):1428-1437.

5. Meddings JA, Reichert H, Rogers MA, Saint S, Stephansky J, McMahon LF. Effect of nonpayment for hospital-acquired, catheter-associated urinary tract infection: a statewide analysis. Ann Intern Med 2012;157(5):305-312.

6. Scott RD. The Direct Medical Costs of Healthcare-Associated Infections in U.S. Hospitals and the Benefits of Prevention. Atlanta: Centers for Disease Control and Prevention, 2009. http://www .cdc.gov/hai/pdfs/hai/scott_costpaper.pdf. Accessed September 11, 2013.

7. Brown PP, Kugelmass AD, Cohen DJ, et al. The frequency and cost of complications associated with coronary artery bypass grafting surgery: results from the United States Medicare program. Ann Thorac Surg 2008;85(6):1980-1986.

8. Agency for Healthcare Research and Quality (AHRQ). HCUPnet: A Tool for Identifying, Tracking, and Analyzing National Hospital Statistics. Rockville, MD: AHRQ, 2013. http://hcupnet .ahrq.gov/. Accessed September 11, 2013.

9. Edwards JR, Peterson KD, Mu Y, et al. National Healthcare Safety Network (NHSN) report: data summary for 2006 through 2008, issued December 2009. Am J Infect Control 2009;37(10): 783-805.

10. Kirkland KB, Briggs JP, Trivette SL, Wilkinson WE, Sexton DJ. The impact of surgical-site infections in the 1990s: attributable mortality, excess length of hospitalization, and extra costs. Infect Control Hosp Epidemiol 1999;20(11):725-730.

11. Lucet JC; Parisian Mediastinitis Study Group. Surgical site infection after cardiac surgery: a simplified surveillance method. Infect Control Hosp Epidemiol 2006;27(12):1393-1396.

12. Kaye KS, Anderson DJ, Sloane R, et al. The effect of surgical site infection on older operative patients. J Am Geriatr Soc 2009; 57(1):46-54.

13. Centers for Disease Control and Prevention (CDC). National Healthcare Safety Network. Atlanta: CDC, 2013. http://www .cdc.gov/nhsn/. Accessed September 11, 2013.

14. Horan TC, Andrus M, Dudeck MA. CDC/NHSN surveillance definition of health care-associated infection and criteria for specific types of infections in the acute care setting. Am J Infect Control 2008;36(5):309-332.

15. University of Minnesota School of Public Health. Research Data Assistance Center. Minneapolis: University of Minnesota, 2013. http://www.resdac.org/. Accessed September 11, 2013.

16. Harvard Pilgrim Health Care Institute; Harvard Medical School. The PAICAP Project. Boston: Harvard Pilgrim Health Care Institute and Harvard Medical School, 2013. http://www.paicap .org/. Accessed September 11, 2013.

17. American Hospital Association (AHA). Annual Survey Database Fiscal Year 2009. Chicago: AHA, 2010.

18. Shadish WR, Cook TD, Campbell DT. Experimental and quasi- experimental designs for generalized causal inference. Boston: Houghton Mifflin, 2002.

19. Sands KE, Yokoe DS, Hooper DC, et al. Detection of postoperative surgical site infections: comparison of health plan-based surveillance with hospital-based programs. Infect Control Hosp Epidemiol 2003;24(10):741-743.

20. Harrington G, Russo P, Spelman D, et al. Surgical-site infection rates and risk factor analysis in coronary artery bypass graft surgery. Infect Control Hosp Epidemiol 2004;25(6):472-476.

21. Berríos-Torres SI, Mu Y, Edwards JR, Horan TC, Fridkin SK. Improved risk adjustment in public reporting: coronary artery bypass graft surgical site infections. Infect Control Hosp Epidemiol 2012;33(5):463-469.

22. Bundy JK, Gonzalez VR, Barnard BM, Hardy RJ, DuPont HL. Gender risk differences for surgical site infections among a primary coronary artery bypass graft surgery cohort: 1995-1998. Am J Infect Control 2006;34(3):114-121.

23. Russo PL, Spelman DW. A new surgical-site infection risk index using risk factors identified by multivariate analysis for patients undergoing coronary artery bypass graft surgery. Infect Control Hosp Epidemiol 2002;23(7):372-376.

24. Friedman ND, Bull AL, Russo PL, et al. An alternative scoring system to predict risk for surgical site infection complicating coronary artery bypass graft surgery. Infect Control Hosp Epidemiol 2007;28(10):1162-1168.

25. Fakih MG, Sharma M, Khatib R, et al. Increase in the rate of sternal surgical site infection after coronary artery bypass graft: a marker of higher severity of illness. Infect Control Hosp Epidemiol 2007;28(6):655-660.

26. Vogel TR, Dombrovskiy VY, Lowry SF. In-hospital delay of elective surgery for high volume procedures: the impact on infectious complications. J Am Coll Surg 2010;211(6):784-790.

27. Agency for Healthcare Research and Quality (AHRQ). Healthcare Cost and Utilization Project: Overview of Comorbidity Software. Rockville, MD: AHRQ, 2013. http://www.hcup-us.ahrq .gov/toolssoftware/comorbidity/comorbidity.jsp. Accessed September 11, 2013.

28. Elixhauser A, Steiner C, Harris DR, Coffey RM. Comorbidity measures for use with administrative data. Med Care 1998;36(1): 8-27.

29. Culver DH, Horan TC, Gaynes RP, et al. Surgical wound infection rates by wound class, operative procedure, and patient risk index. National Nosocomial Infections Surveillance System. Am J Med 1991;91(3B):152S-157S.

30. Platt R, Kleinman $\mathrm{K}$, Thompson $\mathrm{K}$, et al. Using automated health plan data to assess infection risk from coronary artery bypass surgery. Emerg Infect Dis 2002;8(12):1433-1441.

31. Huang SS, Livingston JM, Rawson NS, Schmaltz S, Platt R. Developing algorithms for healthcare insurers to systematically monitor surgical site infection rates. BMC Med Res Methodol 2007;7:20.

32. Huang SS, Placzek H, Livingston I, et al. Use of Medicare claims to rank hospitals by surgical site infection (SSI) risk following coronary artery bypass graft surgery. Infect Control Hosp Epidemiol 2011;32(8):775-783.

33. Calderwood MS, Ma A, Khan YM, et al. Use of Medicare diagnosis and procedures codes to improve detection of surgical site infections following hip arthroplasty, knee arthroplasty, and vascular surgery. Infect Control Hosp Epidemiol 2012;33(1):40 49. 
34. Calderwood MS, Kleinman K, Bratzler DW, et al. Use of Medicare claims to identify US hospitals with a high rate of surgical site infection after hip arthroplasty. Infect Control Hosp Epidemiol 2013;34(1):31-39.

35. Meddings J, Saint S, McMahon LF Jr. Hospital-acquired catheter-associated urinary tract infection: documentation and coding issues may reduce financial impact of Medicare's new payment policy. Infect Control Hosp Epidemiol 2010;31(6):627-633.

36. McNutt $R$, Johnson TJ, Odwazny $R$, et al. Change in MS-DRG assignment and hospital reimbursement as a result of Centers for Medicare \& Medicaid changes in payment for hospitalacquired conditions: is it coding or quality? Qual Manag Health Care 2010;19(1):17-24.

37. Ryan AM. Effects of the Premier Hospital Quality Incentive Demonstration on Medicare patient mortality and cost. Health Serv Res 2009;44(3):821-842.

38. Werner RM, Kolstad JT, Stuart EA, Polsky D. The effect of payfor-performance in hospitals: lessons from quality improvement. Health Aff (Millwood) 2011;30(4):690-698.

39. Ryan AM, Blustein J. The effect of the MassHealth hospital payfor-performance program on quality. Health Serv Res 2011; 46(3):712-728.

40. Tha AK, Joynt KE, Orav EJ, Epstein AM. The long-term effect of premier pay for performance on patient outcomes. $N$ Engl J Med 2012;366(17):1606-1615.

41. Houle SK, McAlister FA, Jackevicius CA, Chuck AW, Tsuyuki $\mathrm{RT}$. Does performance-based remuneration for individual health care practitioners affect patient care?: a systematic review. Ann Intern Med 2012;157(12):889-899.

42. McHugh M, Van Dyke K, Osei-Anto A, Haque A. Medicare's payment policy for hospital-acquired conditions: perspectives of administrators for safety net hospitals. Med Care Res Rev 2011; 68(6):667-682.

43. Hoff T, Hartmann CW, Soerensen C, Wroe P, Dutta-Lin M, Lee G. Making the CMS payment policy for healthcare-associated infections work: organizational factors that matter. $J$ Healthc Manag 2011;56(5):319-335.

44. Centers for Medicare and Medicaid Services; Department of Health and Human Services. Medicare Program; Hospital Inpatient Value-Based Purchasing Program. Fed Regist 2011; 76(88):26490-26547.

45. Centers for Medicare and Medicaid Services; Department of Health and Human Services. Medicare Program; Hospital Inpatient Prospective Payment Systems for Acute Care Hospitals and the Long-Term Care Hospital Prospective Payment System and FY2012 Rates; Hospitals' FTE Resident Caps for Graduate Medical Education Payment; Final Rule. Fed Regist 2011:76 (160):51475-51846.

46. Centers for Disease Control and Prevention (CDC). National Healthcare Safety Network (NHSN): CMS Requirements. Atlanta: CDC, 2013. http://www.cdc.gov/nhsn/cms/index.html. Accessed September 11, 2013.

47. Centers for Medicare and Medicaid Services (CMS). Medicare Hospital Compare. Baltimore: CMS, 2013. http://www .medicare.gov/hospitalcompare/. Accessed September 11, 2013. 